\title{
ME (Ramsay) and ME-International Case Criteria (ME-ICC): two distinct clinical entities
}

\author{
F. N. M. Twisk ${ }^{*}$ (i)
}

Keywords: Myalgic encephalomyelitis, Chronic fatigue syndrome, Case criteria, Diagnosis

The review of the differences and similarities in the different case definitions for myalgic encephalomyelitis (ME)/chronic fatigue syndrome (CFS) by Lim and Son [1] deserves appreciation. Based on their analysis the authors acknowledge the "distinct view of ME and CFS" [2] and recognize four categories of case definitions: ME, ME/CFS, CFS [3] and Systemic Exertion Intolerance Disorder (SEID) [4].

Indeed these labels reflect very different case definitions [5]. According to Lim and Son [1] the first category comprises two 'ME' case definitions: ME (Ramsay) [6] and ME according to the International Case Criteria (ME-ICC) [7]. However as can be deduced from Table 2 [1], ME [6] and ME-ICC [7] are two distinct clinical entities [8].

ME (Ramsay) [6] is a neuromuscular disease. The discriminative symptom of ME is muscle fatiguability/ prolonged muscle weakness following trivial exertion. Ramsay states [9]: "[I]n my opinion a diagnosis should not be made without it". Muscle fatigability is accompanied by "neurological disturbance, especially of cognitive, autonomic and sensory functions" [6]. So, in essence the case definition of ME (Ramsay) [6] is very simple [10] and requires two (types of) symptoms: muscle fatigability/post-exertional muscle weakness and specific neurological symptoms. "Other characteristics include [..] a prolonged relapsing course and variation in intensity of

This comment refers to the article available online at https://doi.org/10.1186/ s12967-020-02455-0.

*Correspondence: frank.twisk@hetnet.nl

ME-de-Patiënten Foundation, Zonnedauw 15, 1906 HB Limmen, The Netherlands symptoms within and between episodes, tending to chronicity." [6].

In contrast, the ME-ICC case definition [7] is much more complex. The diagnosis ME-ICC requires postexertional neuro-immune exhaustion (mandatory symptom), at least three symptoms related to neurological impairments; at least three symptoms related to immune, gastro-intestinal, and genitourinary impairments; and at least one symptom related to energy production or transportation impairments [7].

The case criteria of ME [6] and ME-ICC [7] define two very different patient groups. Muscle fatigability/longlasting post-exertional muscle weakness, a hallmark feature of ME, is not required to be qualified as ME-ICC [7] patient. Symptoms indicating autonomic, sensory, and/or cognitive dysfunction, also mandatory for the diagnosis ME [6], are not required to meet the ME-ICC [7] 'neurological impairments' criterion. The diagnosis ME [6] requires only two type of symptoms (muscle fatigability/ post-exertional muscle weakness and "neurological disturbance"), but the polythetic definition of ME-ICC [7] requires a patient to have at least 8 symptoms. In essence, the case criteria of ME (Ramsay) and ME-ICC are not interchangeable (Fig. 1) [8].

Finally, it is important to note that, in contrast with Table 2 [1], ME [6] is often but not always triggered by an infection and that ME requires at least four symptoms: muscle fatigability/prolonged post-exertional muscle weakness and three neurological symptoms indicative of cognitive, autonomic and sensory dysfunction.

In conclusion, ME (Ramsay) [6], a neuromuscular disease, is not comparable to ME-ICC [7]. ME [6], ME-ICC [7], ME/CFS, CFS [3] and SEID [4] are distinct clinical 


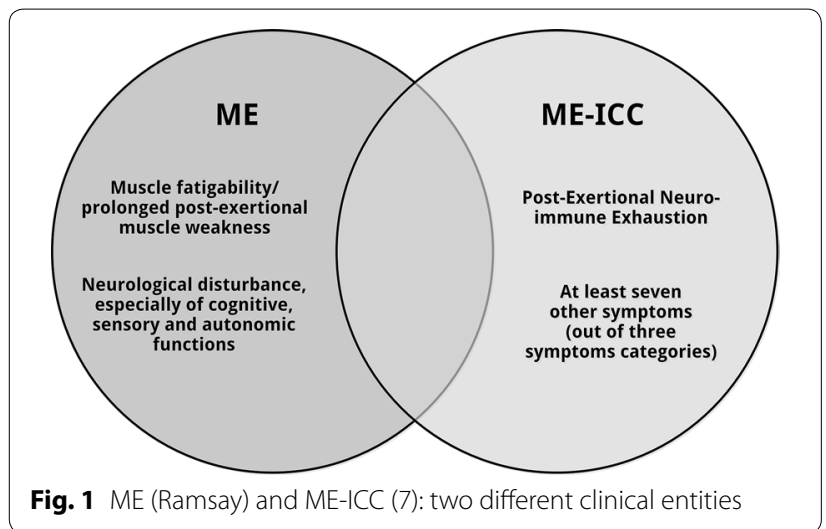

entities with partial overlap. So solving the current confusion with regard to case definitions requires a clear distinction between ME [6], ME-ICC [7], ME/CFS, CFS [3] and SEID [4].

\section{Abbreviations}

ME: Myalgic encephalomyelitis; CFS: Chronic fatigue syndrome; SEID: Systemic Exertion Intolerance Disorder; ME-ICC: ME as defined by the International Case Criteria.

\section{Acknowledgements}

This article is dedicated to Dr. Ramsay, Dr. Dowsett, Dr. Acheson and various others who dedicated their professional career to ME.

\section{Authors' contributions}

The author read and approved the final manuscript.

\section{Funding}

No funding.

\section{Availability of data and materials}

All data related to this study are available in the public domain.

\section{Ethics approval and consent to participate \\ Not applicable.}

\section{Consent for publication}

Not applicable.

\section{Competing interests}

There are no potential conflicts of interest to disclose.

Received: 25 October 2020 Accepted: 10 November 2020

Published online: 25 November 2020

\section{References}

1. Lim EJ, Son CG. Review of case definitions for myalgic encephalomyelitis/ chronic fatigue syndrome (ME/CFS). J Transl Med. 2020;18:289. https:// doi.org/10.1186/s12967-020-02455-0.

2. Twisk FNM. Myalgic encephalomyelitis, chronic fatigue syndrome, and systemic exertion intolerance disease: three distinct clinical entities. Challenges. 2018a:9(1):19. https://doi.org/10.3390/challe9010019.

3. Fukuda K, Straus SE, Hickie I, Sharpe M, Dobbins JG, Komaroff AL. The chronic fatique syndrome: a comprehensive approach to its definition and study. Ann Intern Med. 1994;121(12):953-9. https://doi. org/10.7326/0003-4819-121-12-199412150-00009.

4. Institute of Medicine/National Academy of Medicine. Beyond Myalgic Encephalomyelitis/chronic fatigue syndrome: redefining an illness. Washington, DC: Institute of Medicine/National Academy of Medicine; 2015. ISBN 978-0-309-31689-7.

5. Twisk FNM. Replacing Myalgic Encephalomyelitis and chronic fatigue syndrome with systemic exercise intolerance disease is not the way forward. Diagnostics (Basel). 2016. https://doi.org/10.3390/diagnostics6010 010.

6. Dowsett EG, Ramsay AM, McCartney RA, Bell EJ. Myalgic encephalomyelitis - a persistent enteroviral infection? Postgrad Med J. 1990;66(777):52630. https://doi.org/10.1136/pgmj.66.777.526.

7. Carruthers BM, van de Sande MI, de Meirleir KL, Klimas NG, Broderick $G$, Mitchell T, et al. Myalgic encephalomyelitis: international consensus criteria. J Intern Med. 2011;270(4):327-38. https://doi.org/10.111 1/j.1365-2796.2011.02428.x.

8. Twisk FNM. Myalgic encephalomyelitis or what? The International Consensus Criteria. Diagnostics (Basel). 2018b. https://doi.org/10.3390/diagn ostics9010001.

9. Ramsay AM. Postviral fatigue syndrome-the saga of Royal Free Disease. 1st ed. London (for the Myalgic Encephalomyelitis Association): Gower Medical Publishing; 1986. ISBN 978-0-906-92399-3.

10. Twisk FNM. Myalgic encephalomyelitis or what? An operational definition. Diagnostics (Basel). 2018c. https://doi.org/10.3390/diagnostics8030 064

\section{Publisher's Note}

Springer Nature remains neutral with regard to jurisdictional claims in published maps and institutional affiliations.
Ready to submit your research? Choose BMC and benefit from:

- fast, convenient online submission

- thorough peer review by experienced researchers in your field

- rapid publication on acceptance

- support for research data, including large and complex data types

- gold Open Access which fosters wider collaboration and increased citations

- maximum visibility for your research: over $100 \mathrm{M}$ website views per year

At BMC, research is always in progress.

Learn more biomedcentral.com/submissions 